\title{
OS EFEITOS DE UMA INTERVENÇ̃̃O BREVE EM UMA ESCOLA PÚBLICA: UMA POSSIBILIDADE DE DIZER
}

\author{
LOS EFECTOS DE UNA BREVE INTERVENCIÓN EN UNA ESCUELA PÚBLICA: \\ UNA POSIBILIDAD DE DECIR
}

\author{
THE EFFECTS OF A BRIEF INTERVENTION IN A PUBLIC SCHOOL: A \\ POSSIBILITY OF SAYING
}

\author{
Regina Maria Ayres de Camargo FREIRE ${ }^{1}$ \\ Pauline Luise Von Brusky Sales da Fonseca HERBACH ${ }^{2}$ \\ Ticiana Chiarastelli SALOMÃO ${ }^{3}$
}

RESUMO: Relato de uma forma de intervenção breve em uma escola municipal da cidade de São Paulo, em área de grande vulnerabilidade. O objetivo é apresentar a experiência realizada e seus efeitos sobre as crianças. Duas crianças de 8 anos, passaram pelas entrevistas clínicas de orientação psicanalítica, em número de três a quatro, em atendimento individual. $\mathrm{O}$ relato analisa fragmentos dos dizeres dos envolvidos seguidos de uma síntese do ocorrido em cada entrevista. A análise dos dizeres das crianças foi colocada em relevo, a partir de suporte teórico da psicanálise de vertente lacaniana e indica que uma das crianças não apresenta dificuldades de aprendizagem e a outra, com questões psíquicas, já frequentava um CAPS (centro de atenção psicossocial). Os resultados mostram que, a partir da transferência, as crianças falam de si e de seus impasses e estes podem ser enfrentados de forma discursiva.

PALAVRAS-CHAVE: Psicoterapia breve. Relatos de casos. Educação. Alfabetização.

RESUMEN: Informe de una forma de intervención breve en una escuela municipal de la ciudad de São Paulo, en una zona de gran vulnerabilidad. El objetivo es presentar la experiencia y sus efectos en los niños. Dos niños de 8 años se sometieron a tres o cuatro entrevistas clínicas psicoanalíticas en atención individual. El informe analiza fragmentos de las declaraciones de los involucrados, seguido de un resumen de lo que sucedió en cada entrevista. Se resaltó el análisis de los dichos de los niños, basado en el apoyo teórico del psicoanálisis lacaniano e indica que uno de los niños no tiene dificultades de aprendizaje y el otro, con problemas psíquicos, ya asistió a un CAPS (centro de atención psicosocial). Los resultados muestran que, a partir de la transferencia, los niños hablan de sí mismos y de sus impases y estos pueden enfrentarse de manera discursiva.

PALABRAS CLAVE: Psicoterapia breve. Informes de casos. Educación. Alfabetización.

${ }^{1}$ Pontifícia Universidade Católica de São Paulo (PUC-SP), São Paulo - SP - Brasil. Professora Titular do Departamento de Teorias e Métodos em Fonoaudiologia e Fisioterapia, Faculdade de Ciências Humanas e da Saúde. Doutorado em Educação (PUC-SP). ORCID: https://orcid.org/0000-0002-6116-6165. E-mail: freireregina@uol.com.br

${ }^{2}$ Pontifícia Universidade Católica de São Paulo (PUC-SP), São Paulo - SP - Brasil. Mestranda no PEPG em Fonoaudiologia. ORCID: http://orcid.org/0000-0002-9841-4521.E-mail: lindodia8@yahoo.com.br

${ }^{3}$ Pontifícia Universidade Católica de São Paulo (PUC-SP), São Paulo - SP - Brasil. Psicóloga (USP). ORCID: http://orcid.org/0000-0002-9420-8819.E-mail: tici_salomao@hotmail.com 
ABSTRACT: Report of a form of brief intervention in a municipal school in the city of São Paulo, in an area of great vulnerability. The objective is to present the experience performed and its effects on children. Two 8-year-old children went through clinical interviews of psychoanalytic orientation, in number of three to four, in individual care. The report analyzes fragments of the sayings of those involved, followed by a synthesis of what occurred in each interview. The analysis of the children's statements was highlighted, based on theoretical support of lacanian psychoanalysis and indicates that one of the children does not present learning difficulties and the other, with psychic issues, already attended a CAPS (center of psychosocial care). The results show that, from the transfer, children speak of themselves and their impasses and these can be faced in a discursive way.

KEYWORDS: Brief psychotherapy. Cases reports. Learning. Literacy.

\section{Introdução}

Constata-se que, apesar de todas as iniciativas governamentais e não governamentais para enfrentar as dificuldades de aprendizagem da leitura e da escrita, o índice de analfabetismo ainda é desafiador.

Reconhecendo a distinção entre as duas áreas, psicanálise e educação, o que se questiona é: Como o psicanalista pode intervir com os envolvidos no processo ensino/aprendizagem?

A intervenção clínica orientada pela psicanálise difere de outras práticas psicológicas devido à concepção de sujeito do inconsciente, que a sustenta. Como nos ensina Freud (FERREIRA, 1998, p. 144), o ato educativo é constituído da transmissão de conhecimentos formais, juntamente com uma outra modalidade de transmissão que escapa ao controle consciente. Esta última está para além do campo do saber universal, não sendo possível se assegurar dela.

Assim, o conceito de inconsciente torna-se fundamental, uma vez que interfere no processo de aprendizagem. Trata-se de um saber que escapa ao sujeito ao mesmo tempo que o constitui. Razão pela qual um determinado conteúdo proposto pelo professor afeta o sujeito de maneira particular, causando efeitos e impressões imprevisíveis. Conforme Ferreira (1998, p. 144): “[...] o efeito produzido por aquele que ensina escapa-lhe, posto que existe um saber do qual o sujeito nada sabe e, mesmo sendo desconhecido e estranho ao sujeito, pode sustentar o desejo tanto de saber, quanto de ensinar".

A especificidade da psicanálise está, pois, em localizar o singular do sujeito por trás das ofertas identificatórias propostas pela cultura e pelo discurso da ciência. Essas ofertas levam à alienação do sujeito e reduzem sua dificuldade a um déficit, o que acaba por resultar em sua segregação e exclusão social. A psicanálise não opera com classificações de transtornos, nem 
transtornos padronizados. Foca na dimensão subjetiva da dificuldade de aprendizagem, possibilitando que o sujeito não seja tratado como objeto. Concluindo, não visa o transtorno ou o déficit, mas o sujeito, em sua singularidade.

Sob esse pilar, a possibilidade de trabalho de orientação psicanalítica no ambiente escolar se dá através da oferta de espaços de fala, seja para os gestores, professores, pais ou alunos. A linguagem, por meio da palavra, pode abrir espaço para se "destravar as identificações" (MIRANDA, 2011), ou seja, no deslizar dos significantes abrem-se novas perspectivas de interpretação de uma situação, desfazendo-se as identificações geradoras de impotência e produzindo-se novas saídas.

O objetivo deste relato é descrever uma experiência ocorrida em uma escola do centro da cidade de São Paulo, em que entrevistas clínicas de orientação psicanalítica - ECOP’s - foram a base da intervenção individual com algumas crianças. Estes estudantes foram indicados para o trabalho pelos seus professores e reconhecidos como apresentando resistências ao processo de alfabetização.

\section{As entrevistas clínicas de orientação psicanalítica}

As entrevistas clínicas de orientação psicanalítica são uma intervenção breve, por meio de atendimentos individuais, em que se objetiva conversas com os ditos "alunos-problema", de modo a investigar se essa dificuldade de aprendizagem se trata de um sintoma e que sintoma seria esse, considerando a diversidade que pode ser observada na escola: inibição, angústia, agitação, falta de atenção, atuação, entre outros.

Essa vertente de intervenção permite investigar no discurso das crianças, a partir da orientação da psicanálise lacaniana, quais são as identificações que poderiam estar inibindo a aprendizagem, considerando que elas foram apontadas por seus professores como casos com dificuldades, ou seja, já estão marcadas no discurso da escola como tal. Baseando-se em Lacan, procura-se escutar os significantes que as próprias crianças trazem para reconhecer de que se trata esse impasse, analisando seus dizeres e, a partir da transferência, operando nesse discurso.

Entende-se que, por meio dessas entrevistas clínicas, seja possível investigar quais as respostas individuais que esses alunos estão apresentando frente aos seus impasses subjetivos, de modo a promover um deslocamento da posição subjetiva que impede a criança de aprender. Trata-se de uma intervenção de curta duração e pontual. No caso desta pesquisa, as pesquisadoras tiveram, respectivamente, 4 e 3 encontros com cada uma das crianças, encontros 
esses realizados em uma sala da própria escola, que apresentava condições bastante distintas das de um setting de consultório (ruído, interferência externa, entre outros).

A aplicação desta metodologia, segundo nos mostram Santiago e Assis (2015), resultaria em um deslocamento discursivo da criança, de modo que ela possa ressignificar seu sintoma, descolando-se de uma identificação mortífera e estabelecendo uma nova relação com o conhecimento e com o contexto escolar.

Nesse trabalho, buscou-se repetir essa metodologia de intervenção por parecer bastante adequada para o objetivo de escutar crianças já identificadas com dificuldades, investigar o que está por detrás desses sintomas e promover esse deslocamento. Considerando que o projeto ainda englobava outras frentes de intervenções institucionais, era importante que essas entrevistas ocorressem no próprio contexto escolar, o que permitiu que fossem observadas outras questões sobre o entorno destes alunos. Ainda mais considerando-se que, no caso da intervenção na escola escolhida, temos também o atravessamento do particular contexto social em que grande parte dos estudantes da escola vivem.

Conforme indicado pela experiência do NIPSE, em Minas Gerais, as crianças atendidas foram selecionadas diante da escuta dos casos apontados pelos professores. Procurou-se ter atenção quanto aos sintomas relatados pela equipe, de modo que fossem atendidas justamente as crianças que apresentam um enigma para a escola, crianças sobre as quais os educadores não têm um saber que explique o porquê de elas apresentarem resistências em aprender. Antes de as ditas crianças serem convidadas para as entrevistas, foi realizado um levantamento de dados de cada uma delas, a partir dos documentos escolares como fichas de matrículas e relatórios pedagógicos. No entanto, tivemos dificuldades em localizar muitas informações. Foram realizadas, também, breves conversas com os familiares das crianças, antes e depois da conclusão das entrevistas. No caso da intervenção relatada por Santiago e Assis (2015), havia um apoio pedagógico que poderia ser requisitado como um reforço a ser oferecido para a criança, assim que se avaliasse que o desejo de aprender estivesse instaurado. No entanto, no caso da intervenção a ser relatada neste trabalho, não havia tal serviço a ser disponibilizado para as crianças. Mas cabe ressaltar que a escola oferecia o chamado "reforço escolar" no contra turno, atividade oferecida aos alunos por professor preparado, mas que, no entanto, tinha pouca adesão. 


\section{Material e métodos}

Trata-se de uma pesquisa-intervenção, de caráter clínico, experimental, qualitativo e explicativo que apresenta e discute os efeitos de uma proposta de intervenção junto à alunos do Fundamental 1.

Local: uma escola pública do centro de São Paulo

Sujeitos: 2 crianças cursando o Fundamental I, identificadas pelos professores como apresentando alguns impasses no processo de alfabetização.

Termo de Consentimento Livre Esclarecido: todos os participantes - pais e crianças assinaram o termo de consentimento livre e esclarecido, depois que a pesquisa lhes foi explicada, de acordo com modelo no anexo 1. O termo obteve aprovação do Comitê de Ética sob no 2.247.881 do processo CAAE: 70839817.0.0000.5482.

Os dizeres das crianças e de seus interlocutores foram coletados e transcritos em ortografia regular para permitir a análise de sua materialidade. Sigilo: o nome das crianças foi substituído para preservar sua identidade.

\section{A escola}

Trata-se de uma escola referência na região da baixada do Glicério, na qual gerações de famílias da área estudaram. A baixada do Glicério, por sua vez, é um pequeno bairro de cerca de 4 quilômetros quadrados, localizado ao sul do distrito da Liberdade, na histórica região central de São Paulo onde a cidade foi fundada. Criada em 1940, a baixada é uma região de imigrantes que foi alternando sua aparência conforme o contexto histórico: italianos, portugueses, turcos, asiáticos, haitianos, sul-americanos... Localizada abaixo da Radial Leste, de viadutos e elevados que atravessam em alta velocidade a cidade, a região foi progressivamente abandonada e negligenciada pelo poder público, revelando-se ao primeiro olhar como uma terra de ninguém (SEVCENKO, 2004). É notável o problema da habitação: por toda parte se vê vestígios de moradores de ruas, acolhidos abaixo dos mesmos viadutos ou expostos nas calçadas, assim como uma enorme quantidade de cortiços precários e sujeitos às chuvas e à propagação de doenças (KOHARA, 2009). O Glicério tem a marca da pobreza, negligência do Estado e condições absolutamente precárias de acesso a moradia, serviços de saúde e educação. 


\section{Apresentação e análise dos dados}

\section{João: um menino divido em quatro}

\section{$1^{a}$ entrevista de orientação psicanalítica}

João sai da sala de aula, mostrando uma dificuldade na marcha e na postura enrijecida, enquanto vem pelo corredor com uma de nós, até a sala de Artes.

Ao chegar é tranquilizado: nada de broncas. Contamos que queremos saber um pouco sobre ele João, e como vai na escola. O menino logo começa a falar sem parar.

Em meio a uma longa e detalhada narrativa, que pula de um assunto a outro, sem muita amarração, João fala de sua irmã, Jane, que embora seja dois anos mais nova, é “ de tamanho igual a ele", que "cabe na mesma roupa", que ambos "gostam da mesma pizza de calabresa com queijo". Rapidamente comenta que seu "pai é o tio também". Tentamos resgatar o tema, mas o assunto já foi.

Propomos fazer alguma coisa com o material que temos ali e João diz: “eu não sei escrever, mas vou escrever meu nome": J-O-A-O (analisando o contexto geral da entrevista, essa escrita com tracinhos, nos remeteu ao corpo despedaçado do psicótico) e diz: "estou dividido em quatro palavras". Logo abaixo escreve JANE e diz "estamos juntos". Pontuamos que Jane não está "dividida”. E ele diz: “Jane é tudo junto”. Em seguida, João afirma não saber escrever nenhuma outra palavra. E dizemos que tudo bem, que podemos fazer outras coisas. Ele diz que gosta de desenhar e que "vai ser desenhista". Faz o desenho de uma cabeça, um rosto a lápis e colore com capricho. Diz: "sou eu”. Elogiamos: deu para perceber que é você. João então começa outro rosto, colado ao primeiro. Apaga, e recomeça um pouco mais distante, um outro desenho idêntico. Diz que é seu amigo Rafael. Mais uma vez vemos o "tudo junto" aparecer.

Nessa entrevista, observamos que embora João não saiba escrever, nomeia as letras. Fizemos letras de massinha, escrevemos Rafael e ele reconheceu cada letra, mas não leu o nome. Em seguida, ele aproveita a massinha para fazer figuras disformes e nomeá-las: carimbo, barco, caixa, bolinha, biscoito, ele mesmo, aranha... um discurso sem encadeamento ou pausas significativas. Em um momento, coloca três pedaços de massinha, um ao lado do outro, e aponta para o da ponta, perguntando "o que protege?" e ele mesmo responde animado "sou eu!". Em seguida, junta tudo e diz: "fusão". Ao se despedir pede para levar um pedaço de massinha e trazer da próxima vez, o que entendemos como levar um pouco do vivido ali para casa e garantir o próximo encontro. A massinha é o fio que amarra. E não exatamente o nosso combinado. 


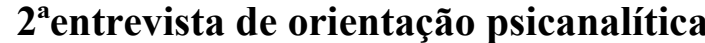

Uma semana depois, na segunda ECOP, João vem cuidadoso com a massinha enrolada em papel e se desculpa: "minha casa é muito gelada, a massinha ficou dura". E repete a dinâmica da primeira entrevista pedindo que adivinhemos determinadas figuras, desta vez feitas em desenho, e vai em um sem fim, até propormos que ele desenhe alguém que goste muito.

Ele desenha sua irmã Jane. É a mesma cabeça dos desenhos anteriores, mas ele modifica o cabelo. E diz: "minha irmã só tem 8 anos, sou bem mais melhor que ela". Pontuamos que sim, existe diferença entre eles. Não são iguais. Ele continua o desenho e, ao chegar o momento do corpo diz: "corpo de menina eu não sei não, mas eu sei sim desenhar a minha irmã". Nesses momentos ele silencia, dizendo alguma frase curta, relacionada ao conteúdo do que registrava. Bem diferente do jeito do seu discurso livre, que sem o apoio do registro vai deslizando erraticamente. Como na primeira entrevista, com relação a representação do amigo, João ressaltou que o cabelo de sua irmã era diferente.

\section{$3^{a}$ entrevista de orientação psicanalítica}

A sala de Artes tinha uma linda exposição de quadros com motivos africanos, pintados pelas crianças. Estavam sobrando diversos potes de guache. Uma sessão com muitas tintas, para a alegria de João que já havia declarado logo de início que "vai ser desenhista".

Uma de nós vai busca-lo. A turma volta do recreio. É possível ver a irmã e João juntos. Além de estudarem na mesma classe, eles parecem gêmeos de tanta semelhança e ficam "grudados".

João senta diante da nossa mesa de trabalho. E começa suas adivinhações:

"o que é tanto mole mas que pode mudar?"

Mudar como?

Ele diz: mudar de cor. A massinha! É mole, mas também é duro. A massinha colorida que troca de cor.

É nesse tropeço da língua, em que cor vira dor, que João pode reconhecer e falar de suas dores.

"Se aperta fica dura, se aperta de novo fica mole". É um potinho de experimento. Você aperta as coisas que tem por dentro. Por dentro vocês sabem o que tem. Por dentro da massinha achou ouro. "Massinha dourada".

"É mole mas também é duro. A massinha colorida que troca de dor". 
Parece que João está falando de si, ele é a "massinha que troca de dor". E como a massinha, às vezes enrijece, retesa o corpo, que parece um boneco de pau ao andar. Às vezes amolece aquele corpo quase desconhecido, que não soube traçar. Precisa de borda, se encosta na gente, no que estiver perto. Ao mesmo tempo em que é uma massinha que por dentro achou ouro. É João, seu próprio potinho de experimento, agora podendo experimentar novas potencialidades em si.

"Hoje eu vou ser o professor. Hoje vou ensinar a colorir com duas cores para fazer artes", ele diz. (que diferença para a criança anteriormente com discurso tão fragmentado e uma imagem corporal "dividida em pedaços: J-O-A-O”).

E passa um bom tempo dessa entrevista psicanalítica, pintando variações de cores, cujo desenho lembra penas diversas e coloridas e muito bem pintadas com guache. Que ele retoca com muita destreza, nuances de dourado. "Vamos fazer dourado de mais cores? Tem que fazer perfeito" ele diz encenando uma aula. "Agora você pode fazer do seu jeito agora" nos recomenda.

"Eu vou fazer de um jeito só meu: dourado com vermelho dá dourado quente”.

Onde o inconsciente, em um lapso da fala, aponta que pode-se mudar a 'dor', provavelmente é possível suportar as 'penas'.

Hoje João chegou mais organizado, parece feliz e orgulhoso. Tem um saber, pode falar de si, e pode nos ensinar. "Verde mais azul é azul raro", continua ele em seus experimentos. Naquilo em que já pode imprimir a sua marca, sua autoria, sua individualidade: suas pinturas.

\section{$4^{\mathrm{a}}$ entrevista de orientação psicanalítica}

Temos mais uma sessão com João, a quarta entrevista, onde o significante dor, reaparece em outras palavras: “circulador”, "guardador". Perguntamos que dor é essa. E João soube localiza-la em seu próprio corpo, além de contar, com maior desenvoltura sobre sua família e as dificuldades. Ele termina a quarta entrevista, criando um abraço de três, entre nós, uma "toca" para ele.

Se despede devolvendo a massinha endurecida que esqueceu no leva e traz da sessão anterior. Não precisa mais dela, já experimentou sua própria plasticidade. Ao mesmo tempo em que pode criar um laço.

Sabemos mais tarde, por sua avó, que João está em tratamento em um CAPS. Mas como vimos antes, isso não parece ser uma questão para sua professora, que ali em uma primeira 
impressão nos pareceu acolher a todos igualmente, "são 30 alunos"... os seus alunos. E talvez essa seja a forma mais justa e possível de falar de inclusão (o lugar social da criança é na escola).

\section{Isaias: o menino com pé no chão, capaz de voar longe}

\section{$1^{a}$ entrevista de orientação psicanalítica}

Com Isaias, o procedimento foi semelhante: uma de nós foi buscar o menino em sua sala de aula para encaminhá-lo até a Sala de Artes, onde se daria a entrevista. Com nossos materiais já citados: massinha de modelar, papel, lápis grafite, borracha e lápis de cor.

Isaias chegou um pouco tímido, preocupado, até lhe explicarmos o que estávamos fazendo ali: entrevistando alguns alunos, não apenas ele. Outros adultos também estavam fazendo essas entrevistas, para conhecer melhor os alunos e saber como estava na escola. Relembramos a ele o dia em que nos encontramos na saída da escola, e conversamos com seu pai. Ele disse que se lembrava de nós.

Pedimos que escrevesse alguma coisa. E ele escreveu seu nome, com calma e capricho. Perguntamos do que ele gostava e se queria escrever sobre isso para nós. Ele registrou, na mesma folha, uma palavra acima da outra: sorvete, futebol, Brasil (o time para o qual torce) e "rodgor" (Rodrigo, seu amigo). Ainda, escreveu a frase "Eu gosto de sorvete". Perguntamos o que ele gostaria de fazer: "desenhar".

E assim propusemos um desenho em conjunto e ele topou (técnica já utilizada em outros trabalhos). E Isaias iniciou desenhando um caminhão. E conforme íamos desenhando, fomos conversando. Isaias nos contou que tem três irmãos menores que ele, que toma conta deles, menos da irmã mais nova. Por que, perguntamos? E ele diz que acha que pensam que poderia derrubá-la. Conta ainda que cuidou dos irmãos menores desde cedo, e que nunca derrubou ninguém. Ao entrar no assunto de família, falou em sua mãe. Perguntamos: como é a sua mãe? "Não me lembro muito bem, só sei que ela é gorda" diz. (Sabemos que a mãe teve uma gravidez e parto complicados e está em repouso, não sabemos como é a compreensão de Isaias com relação a isso). Mas a conversa fluiu assim. Uma de nós desenhou um "fusca" na direção criada por Isaias, a outra desenhou uma bicicleta, na continuidade. O menino, em seguida, desenhou um pássaro e assim o desenho ficou com uma área terrestre e uma aérea. Complementada com um avião, um balão, borboletas, nuvens, sol e aves. Quando lhe indagamos sobre o que estava acontecendo com o eixo da estrada, com o caminhão, o fusca e a bicicleta, ele contou uma história: "Eles estão indo para o Rio de Janeiro pra praia". E pediu para colocar um homem na bicicleta. Uma vez desenhado o homem, lhe perguntamos algo sobre este homem. Ele disse 
que o homem estava pensando na praia, no mar... Uma de nós fez um balão de fala, como nas histórias em quadrinhos. Mas ele a interrompeu e disse que não era assim, que tinha de ser com bolinhas, porque era um pensamento. A outra pesquisadora pontuou que pensar era diferente de falar (tendo em consideração que Isaias nos foi apresentado como uma criança inibida, mas que rapidamente se revelou criativa e aberta ao encontro com o outro) e ele concordou, sorrindo. Continuou, dizendo que eles iam para o Rio e o homem da bicicleta ia entrar no mar, via que tinha um tubarão, mas voltava rápido para a areia, "ele nada muito rápido". Entramos na brincadeira, perguntando quem mais fazia coisas tão rápido e ele falou sobre seu pai. Isaias parece ter no pai uma referência sólida. Quer fazer as coisas como ele quando crescer $e$ trabalhar junto: "vamos fazer cadeiras". Voltou ao desenho. Disse que o balão ia para China e o avião para a Amazônia. Propusemos que ele falasse das pessoas: “ah! as pessoas do balão vão pisar na cabeça de um dragão". E criou diversas estratégias no desenho para que isso acontecesse. O homem da bicicleta se tornou um ladrão de bicicletas. No fusca tinha uma família de 6 pessoas apertadas ali. No caminhão, vinha um bombeiro com água para refrescar. No avião, as pessoas viajavam até a Amazônia para encontrar e recuperar o que o Saci Pererê lhes tinha roubado. Pontuamos algo sobre como é difícil ter algo tirado de si (pensando também na situação de Isaias, com esse irmão bebê que chegou acompanhado de uma mãe em repouso). Propusemos que Isaias fizesse um título para o desenho: VIAJAMTE. Pontuamos quanto ele tinha falado em viagens. E ele então nos conta uma viagem que já fez: foi à Bahia. Que seus avós moram lá. Terminamos a entrevista falando sobre nossa condição de viajantes e o estar de passagem.

\section{$2^{\mathrm{a}}$ entrevista de orientação psicanalítica}

Uma de nós foi buscá-lo em sua sala. A professora parece receptiva. Faz um aceno com o rosto para lsaias. O menino sorri quando vê a pesquisadora. E no caminho entre uma sala e a outra, ela pergunta: você cortou o cabelo? Já bem mais desinibido, ele diz: "não cortei, virei para o outro lado". Ficou bonito, elogia.

O desenho da ECOP anterior está sobre a mesa e lhe perguntamos o que quer fazer com aquele desenho, que parte estava colorido e parte não. Isaias quer fazer uma estrada, por onde passam os veículos desenhados (aquele desenho conta três níveis de narrativas: uma estrada com veículos "que vão para o Rio de Janeiro", o céu onde passa um passarinho e um avião, "indo para a Amazônia" e um balão já mais alto, indo para China. Nas três etapas tem balões 
de "pensamento" onde uma das pessoas está pensando em seu destino: Rio de Janeiro, Amazônia e China.

Diz que quer fazer um novo desenho e passa a fazer uma praia no Rio de Janeiro, onde reporta todo o conteúdo do momento estrada: todos os motoristas estão desfrutando a praia. Ele procura inserir desenhos e sugestões que nós, pesquisadoras, acrescentamos ao desenho anterior. E entendemos como uma inclusão nossa, do tipo: percebo vocês e suas ideias, me lembro do que dissemos e fizemos na sessão passada, vou aproveitar, está sendo importante para mim. É um momento precioso em que o menino, já bastante mais falante, dialoga e traz novos significados para alguns significantes. Exemplo: uma de nós havia desenhado 'protetores' solares, no desenho anterior. Agora Isaias utiliza a palavra protetor, com novo significado: "eles precisam de protetor, eles não sabem nadar. Eles não vão entrar". A cada um dos personagens do desenho anterior e desenhados nesse, Isaias, com muita desenvoltura, vai contando uma história do que eles estão fazendo na praia.

O menino pergunta se queremos desenhar junto. E dizemos que estamos gostando de vê-lo desenhar.

Isaias diz: "tinha uma bola e sumiu. Será que alguém roubou?" Em quase todos os momentos, do desenho anterior que tinha 3 cenas distintas, Isaias se refere a roubo. Ele fez três barracas diante do mar, e finaliza seu desenho com o sol e muitas nuvens ao lado. E diz "vou fazer a Amazônia", já em outro papel. Aqui novamente, sobre as barracas desenhadas diz: "estão de olho, vai que roubam?!"

Ele diz ao final deste desenho: "a Amazônia é bem mais longe que a Bahia". No desenho da China, o menino começa com uma "casa de luta". E um dragão. Diz que não sabe fazer o dragão. E uma de nós sugere: sua ideia é fazer o jacaré e sair mexendo? O menino diz que os “dentes são afiados, mas um pouco pequenos. É pequeno para limpar mais fácil” "Ah! quase esqueci: ele tem asas". Diz: Eles estão falando (as pessoas com relação ao dragão): “olha como ele é grande”. E assim foi a sessão de Isaias. O menino já dando a ver o quanto sua inibição é mesmo uma certa timidez que, em segundo contato, se esvai.

\section{$3^{\text {a }}$ entrevista de orientação psicanalítica}

Quando Isaias entra na sala, na $3^{\mathrm{a}}$ ECOP, todos os desenhos feitos por ele nos dias anteriores estão dispostos sobre a mesa. Ele diz que vai "pintar" o desenho da China, o que ainda não está colorido. Ao mesmo tempo em que começa a colorir, passa a falar: "aqueles da praia estão de férias" (outro desenho). E assim dá a ver a importância que está atribuindo a 
cada entrevista, onde pode expressar, ideias, desenhos e sonhos. Vai mudando de assunto, quer conversar. Diz que o irmão de quatro anos vai de manhã, às 6h para a escola, cedo né? E volta de perua. Ele vai "de pé" para escola. E que na saída o pai ou a mãe buscam. E que agora a mãe está vindo mais (em uma primeira entrevista com o pai, ele contou que sua esposa estava "acamada" por ter tido bebê, 22 dias antes).

Isaias demonstra estar bastante à vontade com as pesquisadoras, enquanto cobre vagarosamente com lápis de cor azul, toda a folha do desenho da China. Notamos que parece querer "encompridar" o tempo que estamos juntos. Como se colorindo devagar o desenho, cobrindo toda a folha (ao invés de um céu em cima e um chão em baixo como fez das outras vezes), ele fizesse o tempo andar mais devagar. Pudesse controlar o tempo desse momento. Isaias continua falando, puxando assunto: “meu pai trabalha na empresa de piso, mas ele gosta de ir na Gazeta só para assistir o jogo de futebol".

Mostra o boneco que desenhou ao lado da casa da China e que parece dançar. Diz: "ele está lutando". "Esse aqui está lutando ne? Mas parece que está dando tchau”. Resposta nossa: Tem alguém mais aqui dando tchau... (ele sabe que é sua última ECOP). Nada dizemos. Esperamos o menino, em seu tempo, associar através de seus desenhos. Ele continua: "este aqui está fazendo uma dança". E por que ele está fazendo uma dança? "É por que ele quer mostrar para o dragão". E o dragão não é perigoso? "Esse aqui não, só os outros”, “as pessoas voaram com o Dragão". E Isaias desenha seu sol e nuvenzinhas que estão em todos os seus desenhos. Você não esquece do sol não é Isaias? (o sol que representa o pai, é presente) "Não", ele diz.

"As arvores (da China) são um pouquinho mais diferentes. Elas têm um verde mais bonito! E plantam frutas, tem muita gente para comer". E aí vai-se vendo a capacidade de imaginar um lugar que nunca viu, de torna-lo concreto pela representação em seu desenho, capaz de contar muitas histórias. Gráfica e verbalmente. Sobre as árvores, agora pintadas ele diz: "É o verde da China".

Isaias desenha uma outra casa e diz que é do "dono da casa de luta". Diz que "dali ele pode ver a casa de luta. Fica de olho. Vai que alguém entra ali e quebra tudo ou rouba né?"

Há uma outra casa, na outra extremidade do papel. Quem mora ali Isaias? “Quem mora na casa verde é o prefeito. Ele gosta mais de verde, ele pinta de verde". Você? Perguntamos. "Não, ele. Ele pinta de verde. Tem cheiro de tinta".

O menino está longe, pintando o céu. Ele mesmo diz sobre aquele tempo encompridado: “Demora muito!" (a pintura que encomprida o tempo). Ele diz também: "poderia ter mais prédio". Por quê? 
"Para mais pessoas morarem”. "E quando a casa fica muito cheia.... tem que viajar". Essa casa está cheia ou vazia? "Cheia”, ele diz. Muito cheia? (Isaias sorri, e parece que entendeu que estamos possivelmente falando da casa dele)

"Não acho que está tão cheia assim não. Pedro mora na casa, ele é tão gordo. Ele ficou magro de tanto pedalar" (Agora refere-se ao desenho do homem na praia, que veio pela estrada de bicicleta) misturando a fantasia com a realidade. Brincando com essa possibilidade.

"Moramos em prédio, meus pais, meus irmãos e o Pedro. O céu tem muito mais espaço né? Mais espaço do que aqui. Tem mais espaço que a cidade”.

Nosso horário está no finalzinho e Isaias propõe fazermos um foguete. Ele diz que sua turma está fazendo um trabalho em dupla, sobre "Violência Doméstica". E concluímos que não adiantaria mesmo voltar agora.

Começamos o foguete, e depois de muitas tentativas, do menino e das duas pesquisadoras, conseguimos dar forma a essa nave. “Às vezes tem que pedir ajuda, não é?" diz ele sobre nossa participação nessa construção do brinquedo.

“O foguete vai para esqueci o nome. O lugar onde tem os marcianos. O piloto é o Jojo! “Jojo é apelido de alguém?" Perguntamos. "Sim, de outro filho do meu pai, com outra mulher. Mais velho."

Não há mais tempo para falar de Jojo, talvez um personagem importante ou misterioso na vida de Isaias, que ele deixa justo para o final, como fazem crianças e adultos em sessão, no desejo de.... encomprida-las. Ou de lançar um assunto importante que não poderá ser falado, por que o tempo acabou. $\mathrm{O}$ foguete fica pronto. Um cilindro de papel sulfite, com um cone como ponta. Isaias verifica se os palitinhos de picolé para fazer as turbinas estão secos (não estão). E desenha uma pequena janela azul em seu foguete. Agora pode ir ainda mais longe.

Combinamos então de deixar secar e entregarmos o foguete a Isaias, na hora da saída.

\section{Discussão}

João se apresentou com grande hesitação com relação à leitura e escrita, revelando dificuldades para registrar outras palavras que não o seu nome e o de sua irmã. No entanto, uma vez no contexto da entrevista e estabelecida uma relação com as psicanalistas, pôde desenvolver uma relação com o mundo das letras, fosse brincando com letras móveis ou montando com massinha. Apesar de apresentar uma barreira, foi capaz de se aproximar de forma lúdica dos registros escritos, deslocando-se de uma posição de recusa. Durante as entrevistas, também ficou evidente a importância de enfatizar uma individualidade para João, que por vezes se 
apresentava praticamente colado à sua irmã Jane, que, inclusive, estuda em sua sala. Talvez por isso se mostre tão dependente, tentando se aproximar com constância da forma de ser da irmã. Assim, nos parece uma boa ideia, que no próximo ano, estejam em turmas separadas. Para garantir a João uma maior autonomia e espaço para ser ele mesmo, sem comparações.

Isaias, por sua vez, chegou às entrevistas como um menino alfabetizado, mas bastante tímido. No entanto, uma vez sob efeito da interação afetiva que se produziu no encontro com as psicanalistas, rapidamente se apropriou do espaço ali proposto e revelou enorme capacidade de concentração e criatividade, produzindo desenhos e histórias que continham uma narrativa complementar e de valor simbólico importante. Apesar de um pouco tímido, nos pareceu mais que Isaias se cala porque presta atenção, escuta, e não porque está inibido ou distraído. Isaias foi reconhecido nessa posição de potência e pode produzir uma escrita livre e desinibida, diretamente pertinente, focada e amarrada ao contexto ao que estávamos inseridos na brincadeira.

É importante que João tenha alguém acompanhando-o de perto para que dê sequência ao seu processo de aproximação do mundo das letras e para que possa apropriar-se da linguagem nos moldes da educação formal. Nos pareceu fundamental que o menino também tenha garantida a sua singularidade, bem como a da sua irmã, de modo que cada um tenha seu percurso individual e separado. Ademais, João já vem sendo tratado há dois anos em CAPS.

Isaias, uma vez submetido a um olhar afetivo, não parece estar tão inibido em mostrar tudo o que já sabe. Alfabetizado e esperto, ao ser reconhecido nesse lugar pode sentir-se seguro para mostrar, como fez conosco, tudo o que já faz e pode fazer. É importante que Isaias não ocupe o lugar de quem não sabe e que suas dificuldades sejam tomadas de forma mais aproximada, facilitando que ele se mostre mais desinibido e livre para devolver tudo que está apreendendo e observando atentamente.

É, portanto, importante que as crianças tenham garantidos espaços de exploração e trocas prazerosas em sala de aula e fora dela, reforçando sua vontade e capacidades de aprender mais, apropriando-se e arriscando-se mais no campo da leitura e da escrita.

\section{Considerações finais}

A experiência das Entrevistas Clínicas de Orientação Psicanalítica na escola traz a possibilidade de promover um giro na posição que esses alunos assumem dentro do contexto escolar. A escuta ofertada a essas crianças, dentro da escola, mas fora do enquadre do grupo da sala de aula, permite que as próprias crianças se reposicionem no seu lugar de aluno e, mais 
ainda, que a equipe escolar (educadores, funcionários, coordenadores) a situem de modo diferente no discurso da instituição.

Com base na eficácia das experiências já relatadas por Santiago e Assis (2015), a aplicação das ECOPs na Escola também se mostrou valorosa e atendeu aos objetivos iniciais do trabalho, apesar da brevidade da intervenção. Uma vez estabelecida a transferência com as psicanalistas, ambos os casos apresentados aqui revelaram mais de sua potencialidade. João se mostrou menos hesitante a se aproximar do mundo das letras e pôde, inclusive, brincar com isso, a partir de seus interesses, convocando as psicanalistas para sustentar essa aproximação que ele fazia a modo próprio e singular. Isso se revelou importante considerando que o garoto possuía uma irmã na escola, à qual frequentemente estava associado. O segundo caso apresentado, Isaías, também pôde se apresentar, sob transferência, de modo completamente distinto do lugar que ocupava no discurso da escola. Revelou-se um menino criativo, cheio de vitalidade e com uma escrita bem expressiva e amarrada ao contexto das brincadeiras que propunha.

Além dos efeitos produzidos nos alunos atendidos, as ECOPs possuem o alcance de devolver para as famílias e para a equipe escolar um outro lugar discursivo possível para essas crianças, promovendo esse giro tão importante para elas quanto para a instituição. Pode-se observar que essa circulação também tem efeitos sobre este suposto saber, inclusive, perante os pares, ou seja, as outras crianças podem ver alguma potencialidade diferente nesses meninos.

Apesar da brevidade do procedimento do procedimento, foi possível tocar em algumas questões simbólicas importantes, mesmo que outras sejam apenas tangenciadas, conforme evidenciado nos relatos clínicos. No entanto, isso não impede que as crianças atendidas ultrapassem suas barreiras e relevem outra posição subjetiva no contexto escolar. Escutadas enquanto sujeitos singulares, fora do grupo, elas podem se reposicionar para, dentro do grupo, assumir um novo lugar.

AGRADECIMENTOS: CNPQ - bolsa de produtividade em pesquisa.

\section{REFERÊNCIAS}

FERREIRA, T. Freud e o ato do ensino. In: LOPES, E. M. T. (Org.) A psicanálise escuta a educação. Belo Horizonte: Autêntica, p. 107-149, 2001.

KOHARA, L. T. Relação entre as condições da moradia e o desempenho escolar: estudo com crianças residentes em cortiços. 2009. 297 f. Tese (Doutorado em Arquitetura e Urbanismo) - Universidade de São Paulo, São Paulo, 2009. 
MIRANDA, M. P. A educação de criança hoje: quando o excesso de sentido segrega o sujeito. In: SANTIAGO, A. L; CAMPOS, R. H. F. (Org). Educação de crianças e jovens na contemporaneidade: pesquisas sobre sintomas na escola e subjetividade. Belo Horizonte: Ed. PUC, p.101-113, 2011.

SANTIAGO, A. L.; ASSIS, R. O que esse menino tem? 1. ed. Belo Horizonte. Editora Sintoma, 2015.

SEVCENKO, N. A cidade metastasis e urbanismo inflacionário: incursões na entropia paulista. Revista USP, São Paulo, n. 63, p. 16-35, set./nov. 2004.

\section{Como referenciar este artigo}

Nome do autor. Os efeitos de uma intervenção breve em uma escola pública: uma possibilidade de dizer. Doxa: Rev. Bras. Psico. e Educ., Araraquara, v. 22, n. 1, p. 209-224, jan./jun., 2020. e-ISSN: 2594-8385. DOI: https://doi.org/10.30715/doxa.v22i1.13362

Submetido em: 03/03/2020

Aceito em: 28/05/2020

Publicado em: 01/06/2020 